\title{
Oncological Outcomes of Pathological T1 Lower Rectal Cancer Patients With or Without Preoperative Chemoradiotherapy
}

\author{
TETSURO TAIRA, HIROAKI NOZAWA, KAZUSHIGE KAWAI, KAZUHITO SASAKI, KOJI MURONO, \\ MANABU KANEKO, SHIGENOBU EMOTO, YUUKI IIDA, HIROAKI ISHII, YUICHIRO YOKOYAMA, \\ HIROYUKI ANZAI, HIROFUMI SONODA and SOICHIRO ISHIHARA \\ Department of Surgical Oncology, The University of Tokyo, Tokyo, Japan
}

\begin{abstract}
Background/Aim: It remains unclear whether rectal cancers down-staged by preoperative chemoradiotherapy (CRT) have similar prognoses to those of the same stage without preoperative CRT. We compared prognoses of $\mathrm{pT} 1$ rectal cancer patients stratified by preoperative CRT. Patients and Methods: We retrieved data of patients with pathological T1 rectal cancer between 2003 and 2020. Patients were divided into the "ypT1 group" who received preoperative CRT following surgery and the "pT1 group" who underwent surgery alone. Factors associated with relapse-free survival (RFS) were investigated. Results: Among 86 patients, ypT1 and pT1 groups comprised 18 and 68 patients, respectively. There was no significant difference in RFS between the groups ( $p=0.19)$. Tumor location within $5 \mathrm{~cm}$ from the anal verge was associated with recurrence (hazard ratio: $0.13, p=0.034$ ). Conclusion: The prognosis of patients with ypT1 rectal cancer was similar to that of patients with pT1. Low tumor location was a poor prognostic factor.
\end{abstract}

Colorectal cancer is the third most commonly diagnosed cancer in males and the second in females worldwide (1). The management of rectal cancer requires multidisciplinary approaches (2). In rectal cancer that does not invade beyond the proper muscle layer, a good prognosis can be achieved by local excision or total mesorectal excision (TME) alone without preoperative chemoradiotherapy (CRT) $(3,4)$. In contrast, preoperative CRT followed by TME is one of the standard treatments for rectal cancer that penetrates the proper muscle layer (5). Preoperative CRT can reduce the local recurrence rate and increase the rate of sphincter

This article is freely accessible online.

Correspondence to: Tetsuro Taira, MD, Department of Surgical Oncology, The University of Tokyo, 7-3-1 Hongo, Bunkyo-ku, Tokyo, 113-8655, Japan. Tel: +81 358008653, Fax: +81 338116822, e-mail: ttaira.tky@gmail.com

Key Words: Preoperative chemoradiotherapy, rectal cancer, prognosis. preservation with a lower toxicity rate than postoperative CRT (6-9). A pathological complete response can be achieved in $10-20 \%$ of patients receiving preoperative CRT and is associated with excellent oncological outcomes (1013). In addition, approximately $40-60 \%$ patients demonstrated down-staging after preoperative CRT (14-16). These rectal cancer patients who exhibited a good response to preoperative CRT also had a favorable prognosis (17-19).

Several studies have reported that the pathological stage was a better predictor for disease-free and overall survival than preoperative stage or response to CRT in rectal cancer patients who received preoperative CRT (14, 20-22). However, it remains unclear whether rectal cancer downstaged by preoperative CRT has a different prognosis from that of the same stage without preoperative CRT. Several groups have previously conducted comparative studies of patients with pathological stage I lower rectal cancer according to preoperative CRT, but the conclusions regarding their prognoses were inconsistent (23-27). Moreover, no similar study confined to pT1 stage has been conducted.

In the current study, we investigated the prognoses of pT1 rectal cancer patients with or without preoperative CRT, and identified prognostic factors among clinicopathological variables.

\section{Patients and Methods}

Patients and clinicopathological parameters. In this retrospective study, we reviewed consecutive patients who had pathological T1 rectal adenocarcinoma located in the lower rectum that was resected by radical surgery at the Department of Surgical Oncology, the University of Tokyo Hospital between August 2003 and January 2020. Patients who underwent trans-anal local excision were excluded from this study. Patients with rectal cancer associated with inflammatory bowel disease and those with suspected lateral pelvic lymph node and/or distant metastases were also excluded.

All resected specimens were assessed pathologically in accordance with the eighth edition of the American Joint Committee on Cancer (28).

The following variables were collected from the medical records: date of operation, sex, age, body mass index (BMI), Eastern 
Cooperative Oncology Group (ECOG) Performance Status (PS), tumor location from the anal verge, tumor size, preoperative serum carcinoembryonic antigen (CEA, the upper limit of normal: 5 $\mathrm{ng} / \mathrm{ml}$ ), surgical procedure, clinical $\mathrm{T}$ and $\mathrm{N}$ stages, pathological $\mathrm{N}$ stage, number of lymph nodes dissected, histological type, lymphatic invasion, venous invasion, and adjuvant chemotherapy (AC). This study was approved by the ethics committee of the University of Tokyo [No. 3252-(10)]

Pretreatment evaluation, preoperative CRT, and surgery. Before treatment, patients were assessed using physical examination, colonoscopy, chest-to-pelvic computed tomography (CT), pelvic magnetic resonance imaging (MRI), and positron emission tomography (PET).

When diagnosed with adenocarcinoma of the rectum with clinical $\mathrm{T} 3$ or T4 stage and/or regional lymph node metastases, patients received preoperative CRT. CRT consisted of a total dose of 50.4 Gy of radiation using the 4-field box technique and concomitant 5fluorouracil (5-FU) - based chemotherapy. Surgery was performed 6-10 weeks after the completion of CRT.

All patients underwent radical surgery based on TME. The surgical procedures included lower anterior resection (LAR), intersphincteric resection (ISR), abdominoperineal resection (APR), and the Hartmann's operation.

Patient classification. Patients who received preoperative CRT and TME-based surgery were classified into the "ypT1 group", whereas those treated by surgery alone were classified into the "pT1 group".

Postoperative follow-up. Whether AC was prescribed to patients was at the doctor's discretion and depended on the patients' preference. All patients underwent a standardized follow-up schedule that included physical examination and serum CEA levels assessment every three months, CT every six months, and annual colonoscopy for at least five years after surgery. Oncological outcomes were evaluated by assessing relapse-free survival (RFS), which was defined as the time between the initial surgery and the date of diagnosis of tumor recurrence in any organ.

Statistical analysis. Categorical variables were compared using the chisquared or Fisher's exact test. Continuous variables were compared using the unpaired t or Mann-Whitney $U$-test. Factors associated with RFS were estimated by univariate and multivariate analyses using the Cox proportional hazards model, where continuous variables were dichotomized by their median or mean values, except for CEA (5 $\mathrm{ng} / \mathrm{ml}$ ) and the number of lymph nodes dissected (12). Only the variables with $p<0.10$ by the univariate analysis were subjected to the multivariate analysis. RFS curves were estimated using the KaplanMeier method and compared using the log-rank test. All analyses were performed using the JMP Pro 15.1 software (SAS Institute Inc, Cary, NC, USA); $p$-values $<0.05$ were considered significant.

\section{Results}

Patient characteristics. As shown in Figure 1, we identified 86 eligible patients. There were 18 patients in the ypT 1 group and 68 patients in the pT1 group. The clinical and pathological characteristics were compared between the ypT1 and pT1 groups (Table I). The clinical T stage $(p<0.001)$ and $\mathrm{N}$ stage

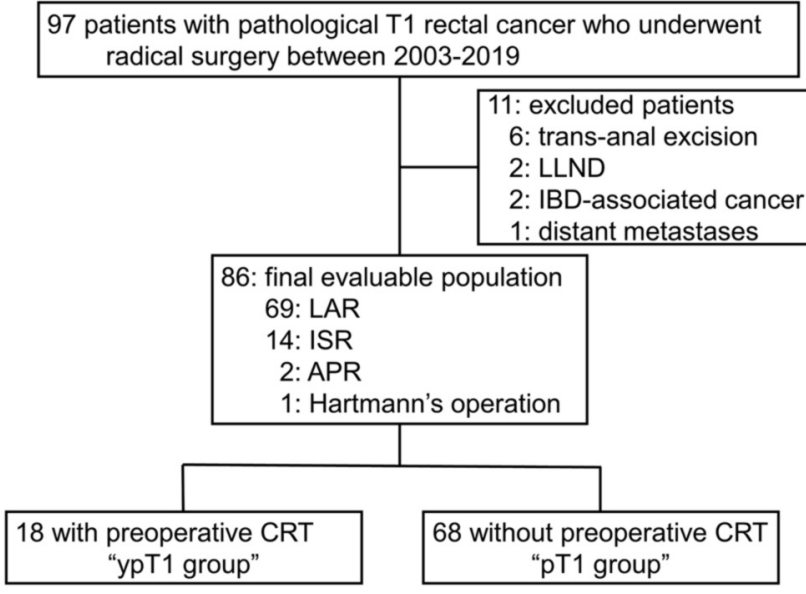

Figure 1. Flowchart of patient enrollment and definition of patient subgroups. LLND: Lateral lymph node resection; IBD: inflammatory bowel disease; LAR: low anterior resection; ISR: intersphincteric resection; APR: abdominoperineal resection; CRT: chemoradiotherapy; yp: pathological data following preoperative chemoradiotherapy; p: pathological data.

$(p<0.001)$ were more advanced in the ypT1 group than in the pT1 group. However, venous invasion was more frequent in the pT1 group than in the ypT1 group (59\% vs. 28\%; $p=0.032$ ). No significant difference was observed in the other preoperative and pathological factors between the two groups.

Follow-up and recurrence. Only one patient (6\%) in the ypT1 group was administered oral 5-FU as AC for six months. No patient in the pT1 group received AC. During the follow-up period (median: 51.1 months for the entire population), three patients in the pT1 group developed recurrence; the involved organs were the lung in two patients and para-aortic lymph nodes in one. No patient in the ypT1 group developed recurrence.

Factors associated with relapse-free survival. To identify prognostic factors associated with RFS, univariate and multivariate analyses were performed. As shown in Table II, tumor location within $5 \mathrm{~cm}$ from the anal verge was a significant factor associated with a poor RFS on univariate analysis $(p=0.020)$. In addition, the body mass index and preoperative CRT were weakly associated with RFS ( $p=0.076$ and $p=0.084$, respectively). By multivariate analysis, only the distance from the anal verge was an independent predictor of RFS (hazard ratio: $0.13, p=0.034$ ).

Relapse-free survival curves by comparison groups. RFS was compared according to preoperative CRT and tumor location. The RFS curve for the ypT1 group did not differ from that for the pT1 group (3-year RFS rate: 100\% vs. 92\%, $p=0.19$; Figure 2A). However, the RFS curve for patients with rectal 
Table I. Patient characteristics.

\begin{tabular}{|c|c|c|c|}
\hline Characteristics & ypT1 $(n=18)$ & pT1 $(n=68)$ & $p$-Value \\
\hline Date of operation & & & 0.062 \\
\hline 2003-2014 & $12(67 \%)$ & $27(40 \%)$ & \\
\hline $2015-2020$ & $6(33 \%)$ & $41(60 \%)$ & \\
\hline Gender & & & 0.12 \\
\hline Male & $7(39 \%)$ & $41(60 \%)$ & \\
\hline Female & $11(61 \%)$ & $27(40 \%)$ & \\
\hline Age, mean \pm SD (years) & $66 \pm 2.6$ & $61 \pm 1.3$ & 0.13 \\
\hline $\mathrm{BMI}$, mean $\pm \mathrm{SD}\left(\mathrm{kg} / \mathrm{m}^{2}\right)$ & $22.6 \pm 0.8$ & $23.4 \pm 0.4$ & 0.34 \\
\hline ECOG PS & & & 1.00 \\
\hline 0 & $18(100 \%)$ & $66(97 \%)$ & \\
\hline $1-2$ & 0 & $2(3 \%)$ & \\
\hline $\begin{array}{l}\text { Distance from anal verge, } \\
\text { mean } \pm S D(\mathrm{~cm})\end{array}$ & $5.8 \pm 0.5$ & $5.4 \pm 0.3$ & 0.44 \\
\hline Size of tumor, mean \pm SD $(\mathrm{mm})$ & $17.9 \pm 3.1$ & $20.3 \pm 1.6$ & 0.50 \\
\hline Preoperative CEA (ng/ml) & & & 0.23 \\
\hline$<5$ & $14(78 \%)$ & $61(90 \%)$ & \\
\hline$\geq 5$ & $4(22 \%)$ & $7(10 \%)$ & \\
\hline Surgical procedure & & & 0.67 \\
\hline LAR & $15(83 \%)$ & $54(79 \%)$ & \\
\hline ISR & $2(11 \%)$ & $12(18 \%)$ & \\
\hline APR & $1(6 \%)$ & $1(1 \%)$ & \\
\hline Hartmann & 0 & $1(1 \%)$ & \\
\hline Clinical $\mathrm{T}$ stage & & & $<0.001$ \\
\hline $\mathrm{cT} 0 / \mathrm{cTis}$ & 0 & $10(15 \%)$ & \\
\hline $\mathrm{cT} 1$ & 0 & $43(63 \%)$ & \\
\hline $\mathrm{cT} 2$ & $1(5 \%)$ & $15(22 \%)$ & \\
\hline cT3 & $16(90 \%)$ & 0 & \\
\hline $\mathrm{cT} 4$ & $1(5 \%)$ & 0 & \\
\hline Clinical N stage & & & $<0.001$ \\
\hline $\mathrm{cN}-$ & $13(72 \%)$ & $68(100 \%)$ & \\
\hline $\mathrm{cN}+$ & $5(28 \%)$ & 0 & \\
\hline No. of LNs dissected & & & 0.60 \\
\hline$<12$ & $10(56 \%)$ & $31(46 \%)$ & \\
\hline$\geq 12$ & $8(44 \%)$ & $37(54 \%)$ & \\
\hline Histological type & & & 0.58 \\
\hline Differentiated & $18(100 \%)$ & $64(94 \%)$ & \\
\hline Others & 0 & $4(6 \%)$ & \\
\hline Lymphatic invasion & & & 0.18 \\
\hline Absent & $17(94 \%)$ & $54(79 \%)$ & \\
\hline Present & $1(6 \%)$ & $14(21 \%)$ & \\
\hline Venous invasion & & & 0.032 \\
\hline Absent & $13(72 \%)$ & $28(41 \%)$ & \\
\hline Present & $5(28 \%)$ & $40(59 \%)$ & \\
\hline Adjuvant chemotherapy & & & 0.21 \\
\hline No & $17(94 \%)$ & $68(100 \%)$ & \\
\hline Yes & $1(6 \%)$ & 0 & \\
\hline
\end{tabular}

P: Pathological data; yp: pathological data following preoperative chemoradiotherapy; SD: standard deviation; BMI: body mass index; ECOG PS: Eastern Cooperative Oncology Group Performance Status; CEA: carcinoembryonic antigen; c, clinical data; LAR: low anterior resection; ISR: intersphincteric resection; APR: abdominoperineal resection; LN: lymph node.

cancer located within $5 \mathrm{~cm}$ from the anal verge was markedly lower than that for the remaining patients (3-year RFS rate: $85 \%$ vs. $100 \%, p=0.014$; Figure 2B).
Table II. Univariate and multivariate analyses of prognostic factors of relapse-free survival.

\begin{tabular}{|c|c|c|c|c|}
\hline \multirow[t]{2}{*}{ Characteristics } & \multirow{2}{*}{$\frac{\text { Univariate }}{p \text {-Value }}$} & \multicolumn{3}{|c|}{ Multivariate } \\
\hline & & HR & $95 \% \mathrm{CI}$ & $p$-Value \\
\hline $\begin{array}{l}\text { Date of operation } \\
(2015-2020 \mathrm{vs.} 2003-2014)\end{array}$ & 0.79 & & & \\
\hline Gender (male vs. female) & 0.24 & & & \\
\hline Age $(\geq 63 v s .<63$ years $)$ & 0.63 & & & \\
\hline BMI $\left(<23 v s . \geq 23 \mathrm{~kg} / \mathrm{m}^{2}\right)$ & 0.076 & 0.19 & $0.01-1.28$ & 0.090 \\
\hline ECOG PS (1-2 vs. 0) & 0.81 & & & \\
\hline $\begin{array}{l}\text { Distance from anal verge } \\
(\geq 5 \mathrm{vs} .<5 \mathrm{~cm})\end{array}$ & 0.020 & 0.13 & $0.01-0.86$ & 0.034 \\
\hline $\begin{array}{l}\text { Tumor size }(\geq 20 \\
v s .<20 \mathrm{~mm})\end{array}$ & 0.64 & & & \\
\hline $\begin{array}{l}\text { Preoperative CEA } \\
(\geq 5 \text { vs. }<5 \mathrm{ng} / \mathrm{ml})\end{array}$ & 0.23 & & & \\
\hline $\begin{array}{l}\text { Clinical T stage } \\
\text { (cT2-4 vs. cT0-1) }\end{array}$ & 0.34 & & & \\
\hline $\begin{array}{l}\text { Clinical N stage } \\
(\mathrm{cN}+v s . \mathrm{cN}-)\end{array}$ & 0.41 & & & \\
\hline $\begin{array}{l}\text { No. of LNs dissected } \\
(\geq 12 \text { vs. }<12)\end{array}$ & 0.21 & & & \\
\hline $\begin{array}{l}\text { Histological type } \\
\text { (others } v s \text {. differentiated) }\end{array}$ & 0.60 & & & \\
\hline $\begin{array}{l}\text { Lymphatic invasion } \\
\text { (present } v s . \text { absent) }\end{array}$ & 0.74 & & & \\
\hline $\begin{array}{l}\text { Venous invasion } \\
\text { (present } v s \text {. absent) }\end{array}$ & 0.70 & & & \\
\hline $\begin{array}{l}\text { Preoperative CRT } \\
\text { (present } v s . \text { absent) }\end{array}$ & 0.084 & $<0.01$ & $<0.01-1.47$ & 0.095 \\
\hline
\end{tabular}

HR: Hazard ratio; CI: confidence interval; BMI: body mass index; ECOG PS: Eastern Cooperative Oncology Group Performance Status; CEA: carcinoembryonic antigen; LN: lymph node; CRT: chemoradiotherapy.

\section{Discussion}

There are limited studies comparing the prognosis of stage I rectal cancer after preoperative CRT (ypT1-2N0M0) with that of treatment-naïve stage I rectal cancer (pT1-2N0M0) (23-27). Wan et al. have reported that ypStage I rectal cancer patients had shorter cancer-specific and overall survivals than pStage I patients by analyzing the Surveillance, Epidemiology, and End Results (SEER) registered database (25). However, in their study, the frequency of ypT2 was $61.2 \%$, a markedly higher percentage than that of pT2 $(33.1 \%, p<0.001)$. Li et al. have used propensity score-matching to analyze 168 matched pairs of rectal cancer patients with ypStage I and pStage I, and demonstrated similar prognoses; however, $45.2 \%$ of ypStage I patients were treated using $\mathrm{AC}$ whereas no pStage I patients received $\mathrm{AC}$, which may have influenced the survival outcomes (27). Moreover, this propensity score matching study and three other reports included only a few (five or less) ypT1 patients $(23,24,26,27)$. To our best knowledge, the current study is the first to compare the prognosis of only 

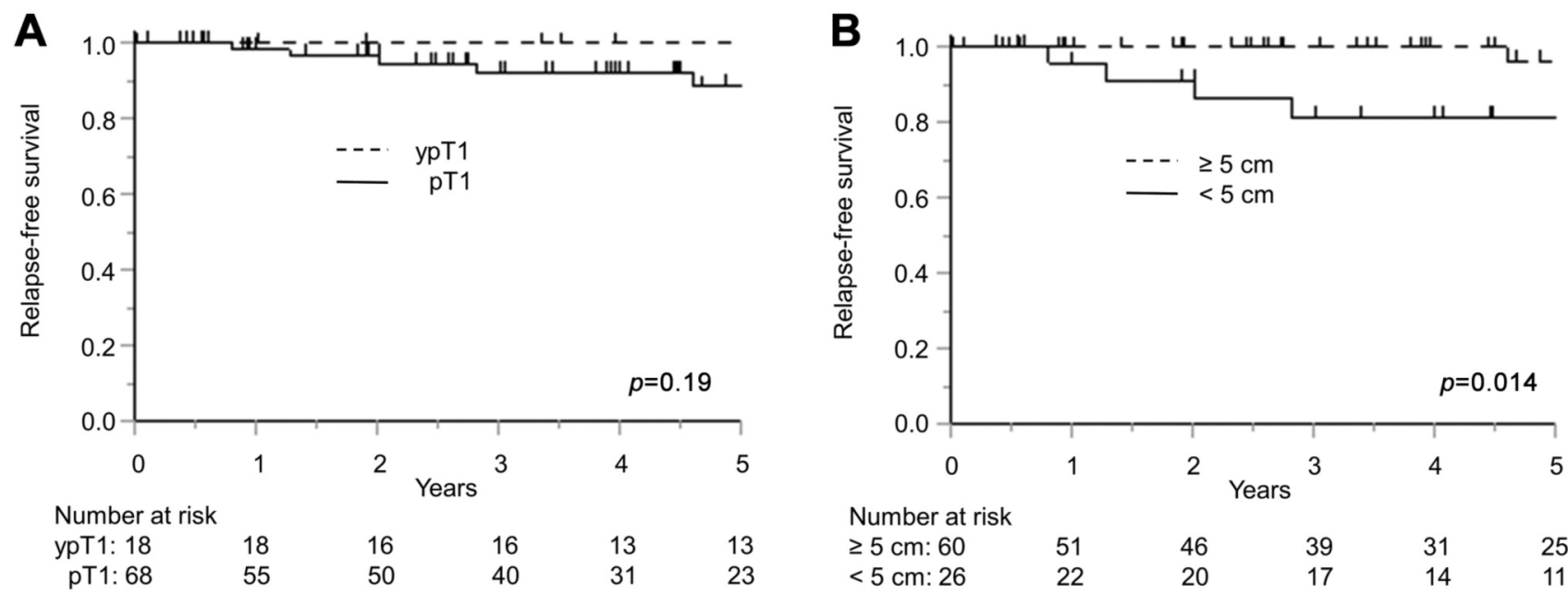

Figure 2. Relapse-free survival (RFS) curves of rectal cancer patients with pathological T1 stage. A) RFS curves stratified by preoperative chemoradiotherapy (ypT1 vs. pT1). B) RFS curves stratified by tumor location from the anal verge $(<5 \mathrm{~cm} v s . \geq 5 \mathrm{~cm})$.

rectal cancer patients with pathological T1 stage, including 18 ypT1 patients. We did not observe a difference in RFS between ypT1 and pT1 patients. In addition, preoperative CRT was not a significant factor for RFS.

In the current study, rectal cancer located within $5 \mathrm{~cm}$ from the anal verge was independently associated with recurrence (hazard ratio: $0.13, p=0.034$ ). Chiang et al. have reported that T3-4 cancers of the lower rectum had a significantly poorer disease-free survival than those of the upper rectum without neoadjuvant therapy (29). Cheng et al. have found that a tumor location within $10 \mathrm{~cm}$ from the anal verge was associated with poor overall survival in stage III rectal cancer without neoadjuvant therapy (30). However, the association between the location of rectal cancer and RFS has not been investigated among patients receiving neoadjuvant therapy or patients confined to pT1 stage.

The benefits of AC in rectal cancer patients who received preoperative CRT remain controversial (16, 31-36). In the ADORE phase 2 trial and the CAO/ARO/AIO-04 phase 3 trial of Stage II and III rectal cancer patients, oxaliplatinbased AC improved DFS $(34,35)$. However, Lu et al. have reported that AC using 5-FU with or without oxaliplatin provided no significant benefit for ypT0-2N0 rectal cancer by retrospectively analyzing 110 patients (37). Therefore, postoperative AC may not be necessary for rectal cancer patients with ypT1N0 stage. Consistent with this, no ypT1 patients had recurrence in our cohort, although only $6 \%$ received 5-FU-based AC. Collectively, further studies with a higher evidence level are required to confirm that $\mathrm{AC}$ has no impact on the survival of (y)pT1 rectal cancer.

The current study contains several other limitations due to its retrospective nature. The study contained only a small number of patients at a single center. As only three patients developed recurrence during the short follow-up period, there may have been type II errors in the identification of prognostic factors. In conclusion, the prognosis of patients with ypT1 rectal cancer did not differ from that of patients with pT1 rectal cancer in the current study. However, only low tumor location from the anal verge was a significant factor for a poor RFS.

\section{Conflicts of Interest}

The Authors declare that they have no conflicts of interest regarding this study.

\section{Authors' Contributions}

T.T. and H.N. contributed to the conception, design and acquisition of data. K.K., K.S., K.M., M.K., S.E., Y.I., H.I., Y.Y., H.A., H.S., and S.I. contributed to the analysis and interpretation of data. T.T. and H.N. contributed to drafting the article. K.K., K.S., K.M., M.K., S.E., Y.I., H.I., Y.Y., H.A., H.S., and S.I. contributed to revising it critically for significant intellectual content. All Authors approved the final version of this manuscript for publication.

\section{Acknowledgements}

This study was supported by Grants-in-Aid for Scientific Research (C: grant number; 18K07194, C: grant number; 19K09114, C: grant number; 19K09115 C: grant number; 20K09051, Challenging Research (Exploratory): grant number; 20K21626) from the Japan Society for the Promotion of Science. This study was supported by the Project for Cancer Research and Therapeutic Evolution (PCREATE), grant number: JP 19cm0106502 from the Japan Agency for Medical Research and Development (AMED). 


\section{References}

1 Bray F, Ferlay J, Soerjomataram I, Siegel RL, Torre LA and Jemal A: Global cancer statistics 2018: Globocan estimates of incidence and mortality worldwide for 36 cancers in 185 countries. CA Cancer J Clin 68(6): 394-424, 2018. PMID: 30207593. DOI: $10.3322 /$ caac. 21492

2 Schmoll HJ, Van Cutsem E, Stein A, Valentini V, Glimelius B, Haustermans K, Nordlinger B, van de Velde CJ, Balmana J, Regula J, Nagtegaal ID, Beets-Tan RG, Arnold D, Ciardiello F, Hoff P, Kerr D, Kohne CH, Labianca R, Price T, Scheithauer W, Sobrero A, Tabernero J, Aderka D, Barroso S, Bodoky G, Douillard JY, El Ghazaly H, Gallardo J, Garin A, Glynne-Jones R, Jordan K, Meshcheryakov A, Papamichail D, Pfeiffer P, Souglakos I, Turhal S and Cervantes A: Esmo consensus guidelines for management of patients with colon and rectal cancer. A personalized approach to clinical decision making. Ann Oncol 23(10): 2479-2516, 2012. PMID: 23012255. DOI: $10.1093 /$ annonc/mds236

3 Winde G, Nottberg H, Keller R, Schmid KW and Bunte H: Surgical cure for early rectal carcinomas (t1). Transanal endoscopic microsurgery $v s$. Anterior resection. Dis Colon Rectum 39(9): 969-976, 1996. PMID: 8797643. DOI: 10.1007/bf02054683

4 Akasu T, Kondo H, Moriya Y, Sugihara K, Gotoda T, Fujita S, Muto $\mathrm{T}$ and Kakizoe $\mathrm{T}$ : Endorectal ultrasonography and treatment of early stage rectal cancer. World J Surg 24(9): 10611068, 2000. PMID: 11036283. DOI: 10.1007/s002680010151

5 Kawai K, Ishihara S, Nozawa H, Hata K, Kiyomatsu T, Tanaka T, Nishikawa T, Otani K, Yasuda K, Murono K, Sasaki K and Watanabe T: Recent advances in neoadjuvant chemoradiotherapy in locally advanced rectal cancer. J Anus Rectum Colon 1(2): 39-44, 2017. PMID: 31583299. DOI: 10.23922/jarc.2017-005

6 Kapiteijn E, Marijnen CA, Nagtegaal ID, Putter H, Steup WH, Wiggers T, Rutten HJ, Pahlman L, Glimelius B, van Krieken JH, Leer JW and van de Velde CJ: Preoperative radiotherapy combined with total mesorectal excision for resectable rectal cancer. N Engl J Med 345(9): 638-646, 2001. PMID: 11547717. DOI: $10.1056 /$ NEJMoa010580

7 Bosset JF, Collette L, Calais G, Mineur L, Maingon P, Radosevic-Jelic L, Daban A, Bardet E, Beny A and Ollier JC: Chemotherapy with preoperative radiotherapy in rectal cancer. N Engl J Med 355(11): 1114-1123, 2006. PMID: 16971718. DOI: 10.1056/NEJMoa060829

8 Sauer R, Becker H, Hohenberger W, Rodel C, Wittekind C, Fietkau R, Martus P, Tschmelitsch J, Hager E, Hess CF, Karstens JH, Liersch T, Schmidberger H and Raab R: Preoperative versus postoperative chemoradiotherapy for rectal cancer. $\mathrm{N}$ Engl $\mathrm{J}$ Med 351(17): 1731-1740, 2004. PMID: 15496622. DOI: 10.1056/NEJMoa040694

9 Crane CH, Skibber JM, Feig BW, Vauthey JN, Thames HD, Curley SA, Rodriguez-Bigas MA, Wolff RA, Ellis LM, Delclos ME, Lin EH and Janjan NA: Response to preoperative chemoradiation increases the use of sphincter-preserving surgery in patients with locally advanced low rectal carcinoma. Cancer 97(2): 517-524, 2003. PMID: 12518377. DOI: 10.1002/cncr.11075

10 Maas M, Nelemans PJ, Valentini V, Das P, Rödel C, Kuo L-J, Calvo FA, García-Aguilar J, Glynne-Jones R, Haustermans K, Mohiuddin M, Pucciarelli S, Small W, Suárez J, Theodoropoulos G, Biondo S, Beets-Tan RGH and Beets GL: Long-term outcome in patients with a pathological complete response after chemoradiation for rectal cancer: A pooled analysis of individual patient data. The Lancet Oncology 11(9): 835-844, 2010. PMID: 20692872. DOI: 10.1016/s1470-2045(10)70172-8

11 Capirci C, Valentini V, Cionini L, De Paoli A, Rodel C, GlynneJones R, Coco C, Romano M, Mantello G, Palazzi S, Mattia FO, Friso ML, Genovesi D, Vidali C, Gambacorta MA, Buffoli A, Lupattelli M, Favretto MS and La Torre G: Prognostic value of pathologic complete response after neoadjuvant therapy in locally advanced rectal cancer: Long-term analysis of $566 \mathrm{ypcr}$ patients. Int J Radiat Oncol Biol Phys 72(1): 99-107, 2008. PMID: 18407433. DOI: 10.1016/j.jirobp.2007.12.019

12 Stipa F, Chessin DB, Shia J, Paty PB, Weiser M, Temple LKF, Minsky BD, Wong WD and Guillem JG: A pathologic complete response of rectal cancer to preoperative combined-modality therapy results in improved oncological outcome compared with those who achieve no downstaging on the basis of preoperative endorectal ultrasonography. Ann Surg Oncol 13(8): 1047-1053, 2006. PMID: 16865595 . DOI: $10.1245 /$ aso.2006.03.053

13 Martin ST, Heneghan HM and Winter DC: Systematic review and meta-analysis of outcomes following pathological complete response to neoadjuvant chemoradiotherapy for rectal cancer. $\mathrm{Br}$ J Surg 99(7): 918-928, 2012. PMID: 22362002. DOI: 10.1002/ bjs. 8702

14 Theodoropoulos G, Wise WE, Padmanabhan A, Kerner BA, Taylor CW, Aguilar PS and Khanduja KS: T-level downstaging and complete pathologic response after preoperative chemoradiation for advanced rectal cancer result in decreased recurrence and improved disease-free survival. Dis Colon Rectum 45(7): 895-903, 2002. PMID: 12130878. DOI: 10.1007/ s10350-004-6325-7

15 Das P, Skibber JM, Rodriguez-Bigas MA, Feig BW, Chang GJ, Wolff RA, Eng C, Krishnan S, Janjan NA and Crane CH: Predictors of tumor response and downstaging in patients who receive preoperative chemoradiation for rectal cancer. Cancer 109(9): 17501755, 2007. PMID: 17387743. DOI: 10.1002/cncr.22625

16 Collette L, Bosset JF, den Dulk M, Nguyen F, Mineur L, Maingon P, Radosevic-Jelic L, Pierart M, Calais G, European Organisation for R and Treatment of Cancer Radiation Oncology G: Patients with curative resection of ct3-4 rectal cancer after preoperative radiotherapy or radiochemotherapy: Does anybody benefit from adjuvant fluorouracil-based chemotherapy? A trial of the european organisation for research and treatment of cancer radiation oncology group. J Clin Oncol 25(28): 4379-4386, 2007. PMID: 17906203. DOI: 10.1200/JCO.2007.11.9685

17 Rodel C, Martus P, Papadoupolos T, Fuzesi L, Klimpfinger M, Fietkau R, Liersch T, Hohenberger W, Raab R, Sauer R and Wittekind C: Prognostic significance of tumor regression after preoperative chemoradiotherapy for rectal cancer. J Clin Oncol 23(34): 8688-8696, 2005. PMID: 16246976. DOI: 10.1200/ jco.2005.02.1329

18 Vecchio FM, Valentini V, Minsky BD, Padula GDA, Venkatraman ES, Balducci M, Micciche F, Ricci R, Morganti AG, Gambacorta MA, Maurizi F and Coco C: The relationship of pathologic tumor regression grade (tgr) and outcomes after preoperative therapy in rectal cancer. Int J Radiat Oncol Biol Phys 62(3): 752-760, 2005. PMID: 15936556. DOI: 10.1016/ j.ijrobp.2004.11.017

19 Ryan R, Gibbons D, Hyland JMP, Treanor D, White A, Mulcahy HE, O'Donoghue DP, Moriarty M, Fennelly D and Sheahan K: Pathological response following long-course neoadjuvant 
chemoradiotherapy for locally advanced rectal cancer. Histopathology 47(2): 141-146, 2005. PMID: 16045774. DOI: 10.1111/j.1365-2559.2005.02176.x

20 Quah HM, Chou JF, Gonen M, Shia J, Schrag D, Saltz LB, Goodman KA, Minsky BD, Wong WD and Weiser MR: Pathologic stage is most prognostic of disease-free survival in locally advanced rectal cancer patients after preoperative chemoradiation. Cancer 113(1): 57-64, 2008. PMID: 18442099. DOI: $10.1002 / \mathrm{cncr} .23516$

21 Kuo LJ, Liu MC, Jian JJM, Horng CF, Cheng TI, Chen CM, Fang WT and Chung YL: Is final tnm staging a predictor for survival in locally advanced rectal cancer after preoperative chemoradiation therapy? Ann Surg Oncol 14(10): 2766-2772, 2007. PMID: 17551794. DOI: 10.1245/s10434-007-9471-z

22 Chan AKP, Wong A, Jenken D, Heine J, Buie D and Johnson D: Posttreatment tnm staging is a prognostic indicator of survival and recurrence in tethered or fixed rectal carcinoma after preoperative chemotherapy and radiotherapy. Int Radiat Oncol Biol Phys 61(3): 665-677, 2005. PMID: 15708244. DOI: 10.1016/j.ijrobp.2004.06.026

23 Du CZ, Chen YC, Cai Y, Xue WC and Gu J: Oncologic outcomes of primary and post-irradiated early stage rectal cancer: A retrospective cohort study. World J Gastroenterol 17(27): 32293234, 2011. PMID: 21912472. DOI: 10.3748/wjg.v17.i27.3229

24 Huh JW, Kim CH, Kim HR and Kim YJ: Oncologic outcomes of pathologic stage i lower rectal cancer with or without preoperative chemoradiotherapy: Are they comparable? Surgery 150(5): 980-984, 2011. PMID: 21875732. DOI: 10.1016/j.surg. 2011.06 .018

25 Wan JF, Zhu J, Li GC, Sun WJ and Zhang Z: Ypt1-2n0 rectal cancer after neoadjuvant chemoradiation has lower survival compared with pt1-2n0 rectal cancer. Oncotarget 6(38): 4105641062, 2015. PMID: 26517674. DOI: 10.18632/oncotarget.5379

26 Yeop Oh S, Bae Kim Y and Wook Suh K: Oncologic outcome of ypt1-2n0 rectal cancer after neoadjuvant chemoradiotherapy compared with pt1-2n0 rectal cancer. Am J Clin Oncol 40(5): 512-516, 2017. PMID: 26083556. DOI: 10.1097/coc. 0000000000000196

27 Li N, Jin J, Yu J, Li S, Tang Y, Ren H, Liu W, Wang S, Liu Y, Song Y, Fang H, Yu Z and Li Y: Down-staging depth score to predict outcomes in locally advanced rectal cancer achieving ypi stage after neoadjuvant chemo-radiotherapy versus de novo stage pi cohort: A propensity score-matched analysis. Chin J Cancer Res 30(3): 373-381, 2018. PMID: 30046231. DOI: $10.21147 /$ j.issn.1000-9604.2018.03.09

28 Weiser MR: AJCC 8th edition: Colorectal cancer. Ann Surg Oncol 25(6): 1454-1455, 2018. PMID: 29616422. DOI: 10.1245/ s10434-018-6462-1

29 Chiang JM, Hsieh PS, Chen JS, Tang R, You JF and Yeh CY: Rectal cancer level significantly affects rates and patterns of distant metastases among rectal cancer patients post curative-intent surgery without neoadjuvant therapy. World J Surg Oncol 12: 197, 2014. PMID: 24980147. DOI: 10.1186/1477-7819-12-197

30 Cheng LJ, Chen JH, Chen SY, Wei ZW, Yu L, Han SP, He YL, Wu ZH and Chen CQ: Distinct prognosis of high versus mid/low rectal cancer: A propensity score-matched cohort study. J Gastrointest Surg 23(7): 1474-1484, 2019. PMID: 30617772. DOI: $10.1007 / \mathrm{s} 11605-018-04072-1$

31 Breugom AJ, Swets M, Bosset J-F, Collette L, Sainato A, Cionini L, Glynne-Jones R, Counsell N, Bastiaannet E, van den Broek
CBM, Liefers G-J, Putter H and van de Velde CJH: Adjuvant chemotherapy after preoperative (chemo)radiotherapy and surgery for patients with rectal cancer: A systematic review and metaanalysis of individual patient data. Lancet Oncol 16(2): 200-207, 2015. PMID: 25589192. DOI: 10.1016/s1470-2045(14)71199-4

32 Bosset J-F, Calais G, Mineur L, Maingon P, Stojanovic-Rundic S, Bensadoun R-J, Bardet E, Beny A, Ollier J-C, Bolla M, Marchal D, Van Laethem J-L, Klein V, Giralt J, Clavère P, Glanzmann C, Cellier P and Collette L: Fluorouracil-based adjuvant chemotherapy after preoperative chemoradiotherapy in rectal cancer: Long-term results of the eortc 22921 randomised study. Lancet Oncol 15(2): 184-190, 2014. PMID: 24440473. DOI: 10.1016/s1470-2045(13)70599-0

33 Glynne-Jones R, Counsell N, Quirke P, Mortensen N, Maraveyas A, Meadows HM, Ledermann J and Sebag-Montefiore D: Chronicle: Results of a randomised phase iii trial in locally advanced rectal cancer after neoadjuvant chemoradiation randomising postoperative adjuvant capecitabine plus oxaliplatin (xelox) versus control. Ann Oncol 25(7): 1356-1362, 2014. PMID: 24718885. DOI: 10.1093/annonc/mdu147

34 Hong YS, Nam BH, Kim KP, Kim JE, Park SJ, Park YS, Park JO, Kim SY, Kim TY, Kim JH, Ahn JB, Lim SB, Yu CS, Kim JC, Yun SH, Kim JH, Park JH, Park HC, Jung KH and Kim TW: Oxaliplatin, fluorouracil, and leucovorin versus fluorouracil and leucovorin as adjuvant chemotherapy for locally advanced rectal cancer after preoperative chemoradiotherapy (adore): An openlabel, multicentre, phase 2, randomised controlled trial. Lancet Oncol 15(11): 1245-1253, 2014. PMID: 25201358. DOI: 10.1016/s1470-2045(14)70377-8

35 Rodel C, Graeven U, Fietkau R, Hohenberger W, Hothorn T, Arnold D, Hofheinz RD, Ghadimi M, Wolff HA, LangWelzenbach M, Raab HR, Wittekind C, Strobel P, Staib L, Wilhelm M, Grabenbauer GG, Hoffmanns H, Lindemann F, Schlenska-Lange A, Folprecht G, Sauer R and Liersch T: Oxaliplatin added to fluorouracil-based preoperative chemoradiotherapy and postoperative chemotherapy of locally advanced rectal cancer (the german cao/aro/aio-04 study): Final results of the multicentre, open-label, randomised, phase 3 trial. Lancet Oncol 16(8): 979-989, 2015. PMID: 26189067. DOI: 10.1016/s1470-2045(15)00159-x

36 Sainato A, Cernusco Luna Nunzia V, Valentini V, De Paoli A, Maurizi ER, Lupattelli M, Aristei C, Vidali C, Conti M, Galardi A, Ponticelli P, Friso ML, Iannone T, Osti FM, Manfredi B, Coppola M, Orlandini C and Cionini L: No benefit of adjuvant fluorouracil leucovorin chemotherapy after neoadjuvant chemoradiotherapy in locally advanced cancer of the rectum (larc): Long term results of a randomized trial (i-cnr-rt). Radiother Oncol 113(2): 223-229, 2014. PMID: 25454175. DOI: 10.1016/j.radonc.2014.10.006

$37 \mathrm{Lu} \mathrm{Z}$, Cheng P, Zhang MG, Wang XS and Zheng ZX: Is adjuvant chemotherapy necessary for patients with ypt0-2n0 rectal cancer treated with neoadjuvant chemoradiotherapy and curative surgery? Gastroenterol Rep (Oxf) 6(4): 277-283, 2018. PMID: 25454175. DOI: 10.1093/gastro/goy029

Received August 31, 2020

Revised September 12, 2020 Accepted September 13, 2020 